\begin{tabular}{|c|c|}
\hline $4 E$ European Association for the & $\begin{array}{c}\text { International Conference on Renewable Energies and Power Quality } \\
\text { (ICREPQ'12) }\end{array}$ \\
$\begin{array}{c}\text { Development of Renewable Energies, Environment } \\
\text { and Power Quality (EA4EPQ) }\end{array}$ & Santiago de Compostela (Spain), 28th to 30th March, 2012 \\
\hline
\end{tabular}

\title{
Smart Structural Control Strategies for Offshore Wind Power Generation with Floating Wind Turbines
}

\author{
Ningsu Luo ${ }^{1}$, Lluís Pacheco ${ }^{2}$, Yolanda Vidal ${ }^{3}, \mathrm{Hui}^{4}{ }^{4}$ \\ ${ }^{1}$ Institute of Informatics and Applications, University of Girona, Girona, Spain. \\ +34972418 888, ningsu.luo@udg.edu \\ 2 Institute of Informatics and Applications, University of Girona, Girona, Spain. \\ +34972418 887, lluis.pacheco@udg.edu \\ ${ }^{3}$ Department of Applied Mathematics III, UPC - Barcelona Tech, Barcelona, Spain. \\ + 34934137 309, yolanda.vidal@upc.edu \\ ${ }^{4}$ School of Civil Engineering, Harbin Institute of Technology, Harbin, China. \\ + 864518628 2013, lihui@hit.edu.cn
}

\begin{abstract}
Offshore wind energy is one of the fastest growing powers in the field of renewable energy. An offshore wind farm situated sufficiently far away from the coast can generate more wind power and will have a longer operation life since the wind is stronger and more consistent than that on or near the coast. It can also avoid some major problems of the traditional wind farms like the visual and noise impacts and potential damage to wildlife. From the technical point of view, it is difficult to anchor the wind turbines directly on the seabed in deep water. Thus, new constructive solutions based on floating support structures are proposed. One of the main challenges is to reduce the fatigue of a floating offshore wind turbine so as to guarantee its proper functioning under the constraints imposed by the floating support structures subject to a greater range of motion than that of the fixed-bottom support structures. This paper analyzes the loads and dynamic response of floating support structures and proposes the smart control strategies for mitigating the dynamic wind and wave loads on floating wind turbines.
\end{abstract}

\section{Key words}

Floating wind turbines, offshore wind energy, smart structural control systems, analysis of dynamic loads and vibration control.

\section{Introduction}

In recent years, offshore wind energy [1]-[5] is the fastest growing clean and renewable energy source in the world. However, most of the wind farm development has been limited to the land space and shallow water regions. Recently, several European countries (including Spain),
USA, Japan and China have started to plan floating offshore wind farms. In June of 2009, the first floating offshore wind turbine of the world "Hywind" was installed by Statoil-Hydro and Siemens on the coast of Karmøy, near the port of Bergen, Norway.
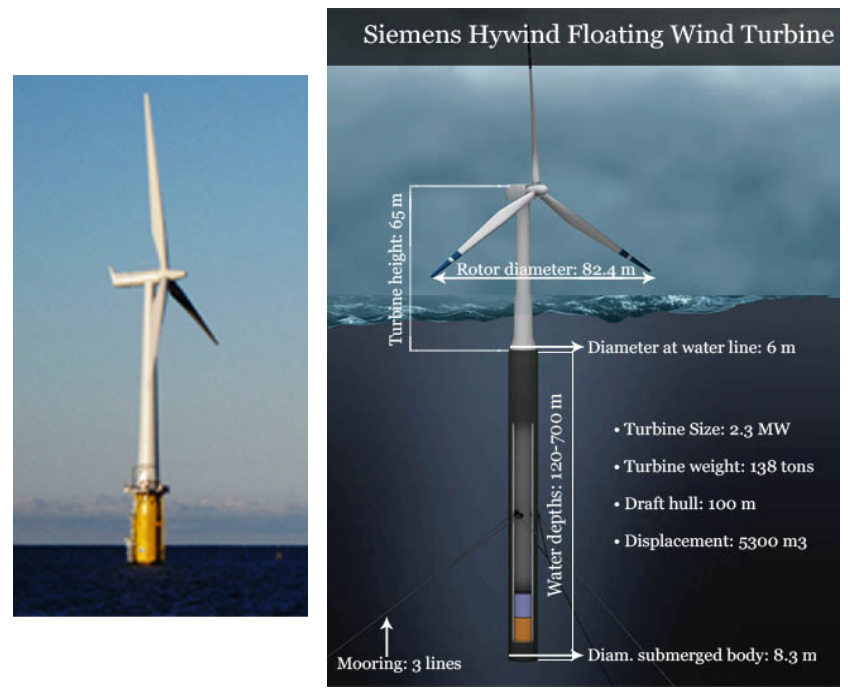

Figure 1: First floating offshore wind turbine Hywind

In general, floating offshore wind farms are considered to be more difficult to design and install. However, in deep waters they are less sensitive to the space availability, noise restriction, and visual pollution, among others. Moreover, the wind power generation is more effective 
due to that floating offshore wind farms are exposed to a much stronger and steadier wind field.

Spain, as the second largest installed capacity in Europe, is known for its use of onshore wind. However, there is not any offshore wind farm installed in Spain yet. A recently published wind map by the Institute for Energy Diversification and Saving of Energy indicated that the offshore wind in Spain could also generate large amount of energy. According to Greenpeace, in the Iberian Peninsula it would be possible to create $25,000 \mathrm{MW}$ by the year of 2030, which would avoid the annual emission of 25 million tons of $\mathrm{CO}_{2}$. The navy terrain in Spanish Mediterranean Sea wins a lot of depth moving a bit away from the coast. Thus, Spain is considered as one of the European countries with great interests in floating offshore wind farms. Recently, Spain also identified some key floating structures for the future of offshore wind energy and added them to the technological development through the project "EMERGE", which is an initiative funded by the Ministry of Science and Innovation aiming to the installation of floating offshore wind farms in deep water. The Spanish government proposed this Special Strategic Project Plan to generate awareness and position the companies and institutions in this new research fields. "ZEFIR" is another floating project under development in Catalonia, which aims to develop pioneer technologies for wind energy production by building a pilot plant for offshore wind farms, and raises the installation of multiple floating offshore turbines in deep water of Tarragona, Spain. In 2007, the Spanish government published an environmental strategy study of the Spanish coast, in delimiting the areas that meet the conditions for the installation of offshore wind farms and established a procedure for offshore wind farm installation larger than $50 \mathrm{MW}$.

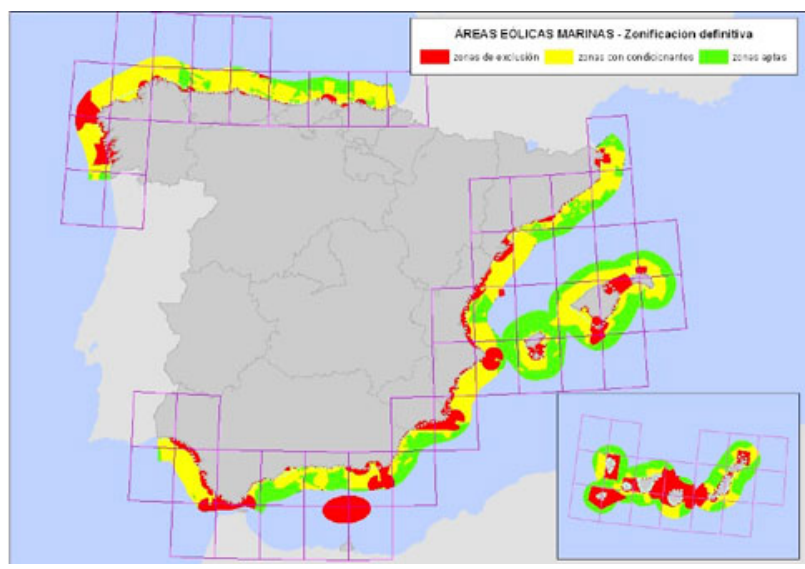

Figure 2: Map of potential offshore wind farms in Spain

This paper addresses the problem of mitigating the dynamic load responses of floating offshore wind turbines, which might cause undesirable vibrations and affect the structure integrity and system performance. First, the floating support platforms are described. Then, the wind and wave dynamic loads are analyzed. Finally, smart structural control techniques, especially the semiactive Tuned Liquid Column Damper (TLCD), are presented for achieving the stability and reliability of the floating wind turbines and for extending the their fatigue life so as to enhance the offshore wind power generation.

\section{Offshore wind power generation}

The majority of offshore wind farms in Europe are installed in Nordic Sea due to its shallow water depth (less than $30 \mathrm{~m}$ ) by using the fixed support platforms (classic, spar and Tension Leg Platform - TLP) for the offshore wind turbines [11].

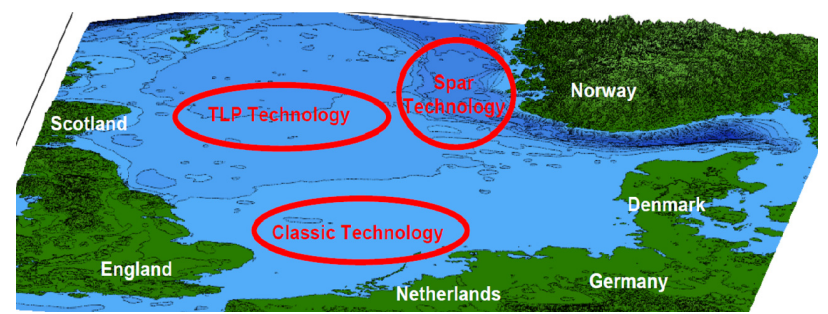

Figure 3: Offshore wind farms in Nordic Sea

The development of offshore wind turbines with fixed support platforms is based on the experiences of onshore wind turbines. Thus, it opened a relatively short path of success for the installation of offshore wind farms in shallow water. In a fixed offshore wind turbine, the highfrequency excitations caused by rotating blades and tower flexibility may cause resonance at its natural frequencies. Consequently, it may significantly shorten its fatigue life when the water depth increases [5].

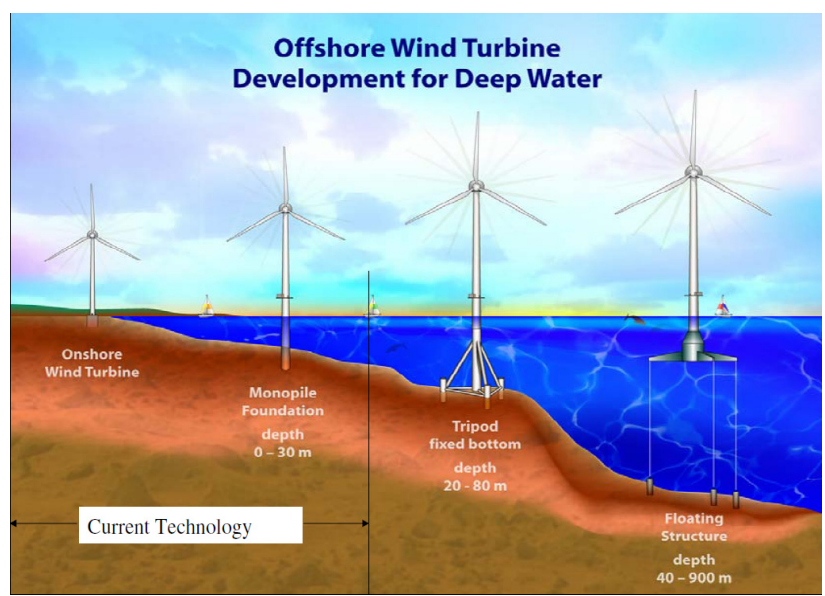

Figure 4: Offshore wind turbine development

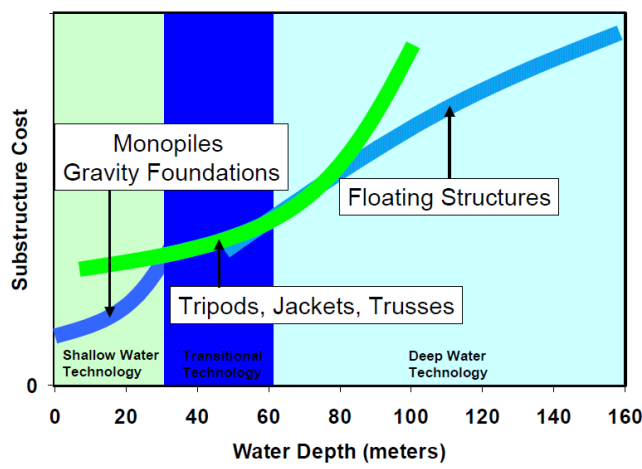

Figure 5: Support platforms for offshore wind turbines 
The floating support platforms provide with an effective solution to the installation of offshore wind turbines in deep water. If technology and infrastructure are fully developed, floating offshore wind farms are expected to produce huge amount of clean electricity at a competitive price compared to other energy sources. However, floating offshore wind farms have the following disadvantages: 1) more transmission loss, more complex blade control due to body motions; 2) larger inertia loading on tall tower caused by greater floater accelerations; 3) possibly more expensive and complicated installation processes (including mooring lines). Also, since floating wind turbines are directly exposed to the open ocean without any natural protection, they may have to endure harsher environments.

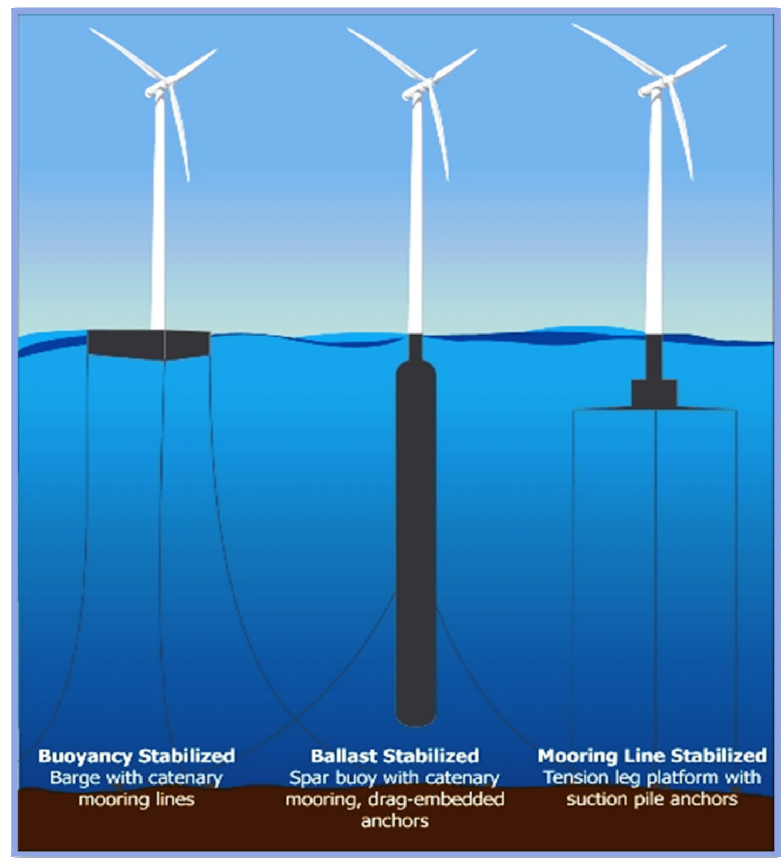

Figure 6: Floating support platforms (buoyancy stabilized, ballast stabilized and mooring line stabilized)

In general, the natural frequencies of floating offshore wind turbines are typically much lower than those of the rotor-induced or the tower-flexibility-induced excitations [11]. The possibility of dynamic resonance with the tower and blades is much less, with the exception of the TLP which are much stiffer in the vertical-plane. For other types of floating bases with softer mooring system, such as spar or semi-submersible, the low-frequency excitations related to the blade pitch-angle control may cause largeamplitude slowly-varying floater motions. Therefore, the accurate estimation of the coupling effects between the floater dynamics and tower-blade dynamics/control is very important in the optimal design of floating offshore wind turbines.

For the design and installation of the support platforms of floating offshore wind turbines, the existing technology and experience of offshore petroleum and natural gas industries are directly applicable.

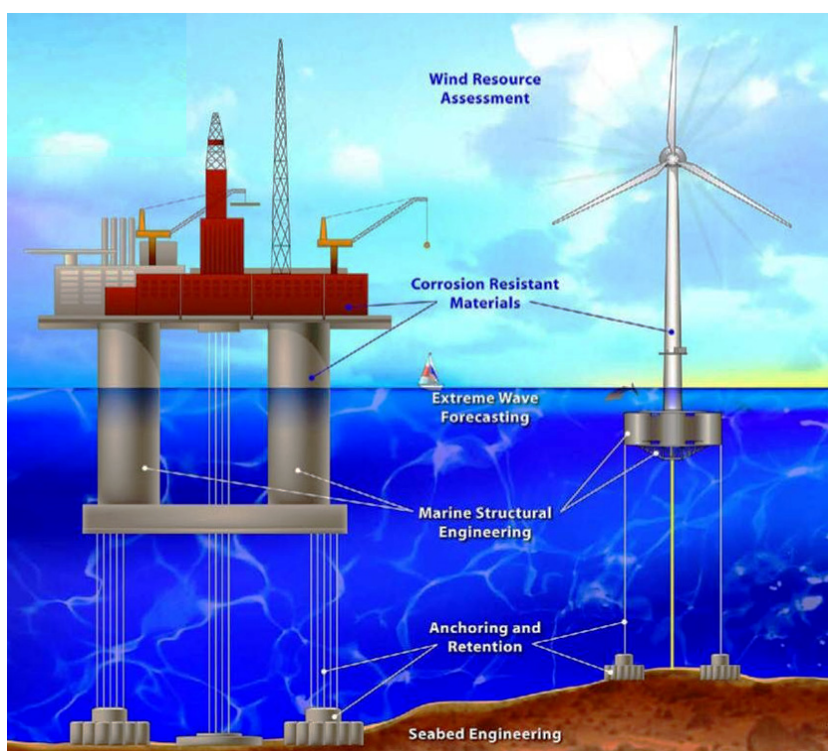

Figure 7: Technology and experience transferable to floating support platforms of wind turbines

\section{Dynamic wind and wave loads}

Floating wind turbine modeling can be broken into the following distinct but related areas: aerodynamics, hydrodynamics, turbulent inflow, foundation dynamics and structural dynamics. A major difficulty in the control of floating offshore wind turbine is the presence of the aerodynamic loads (wind turbulence) and hydrodynamic loads (wave current), which are generally stochastic ones.

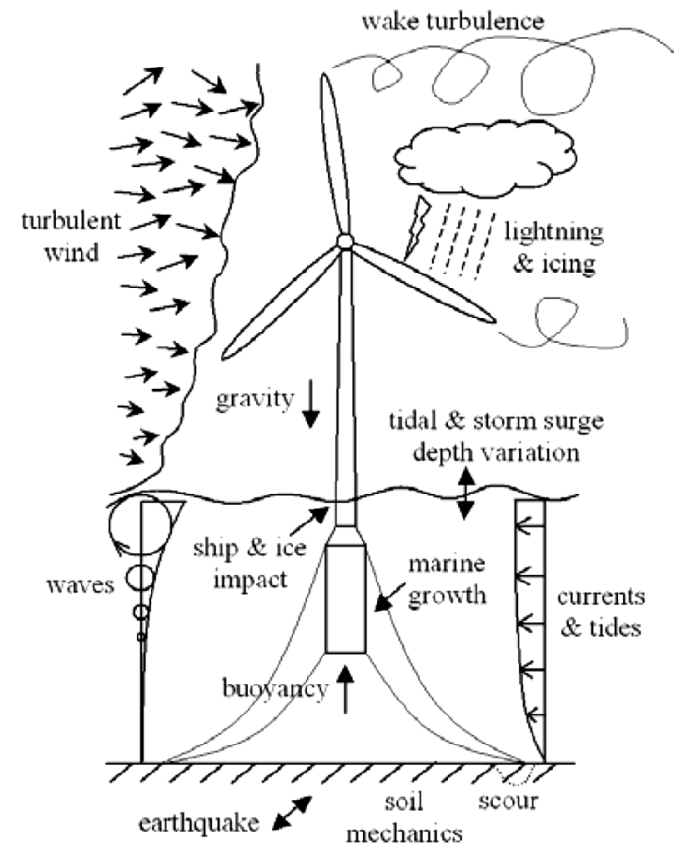

Figure 8: Wind and wave dynamic loads

Modeling aerodynamics is critical for predicting how the varying winds are transformed into power and the aerodynamic loads that affect wind turbine performance [6]-[7]. The wind is by nature a highly stochastic process involving many different length and time scales. International design standards have sought to quantify the 
wind inflow in terms of both extreme events and also smaller scale stochastic variability. In addition to the mean wind speed and turbulence levels, wind shear is another important variable for load production. In general, aerodynamic models tend to have the greatest uncertainty of all the modeling regimes, given the potential for nonlinear behavior.

The prediction of hydrodynamic loads that affect the floating support platforms is an active research topic [8]. The hydrodynamics depend on the foundation system and water depth for the offshore turbine installation. Since wind turbines operating in this environment are floating, the platform motions affect the incoming wave dynamics [9]-[10]. Consequently, the experience of onshore wind turbines cannot be applied directly to the development of floating wind turbines. In general, the fatigue loads govern most parts of the support platform design [11]. For these loads, the effects of wind-wave directional distribution and misalignment, damping and associated dynamic amplification, play a dominant role. For floating wind turbines, the support platforms are considered compliant and have large motions. The dynamic responses of the floating wind turbines and support platforms are strongly coupled [12]-[13]. The floating structural dynamics depend on how the support platform be stabilized by ballast, mooring lines or buoyancy [14]. The effect of support platform motion on the strength of the blades and shafting is a key issue to be investigated for designing the wind turbine and support platform [11].

\section{Smart structural control techniques}

Control systems play an important role in maximizing the wind power generation and guaranteeing the overall stability of wind turbine systems to damp the undesirable structural resonances and reduce the dynamic response to the wind turbulence and wave current. For floating offshore support platforms, a big challenge is in damping the roll motions, which are translations of the rotor in the plane of rotation. Additionally, in contrast to the fixed offshore wind turbines, control systems should be used to limit the responses of the floating wind turbine and floater platform to the stochastic wave loading.

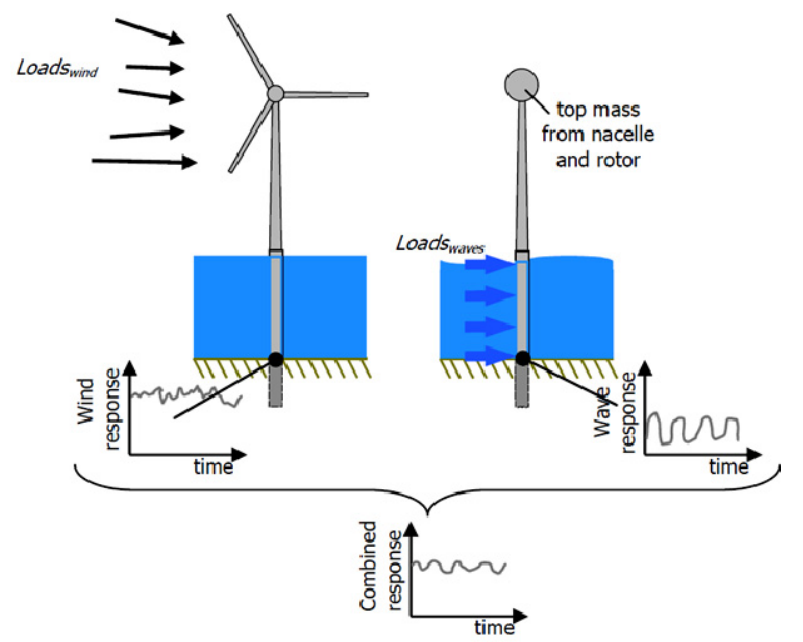

Figure 9: "Dry" and "wet" dynamics of a floating wind turbine
The response of floating offshore wind turbines is strongly affected by the "wet" hydro-elastic part of the machine; i.e. the hydrodynamic loads on the submerged part of the tower give rise to hydro-elastic effects, due to the flexibility of the tower itself and/or the interaction with the mooring system for floating platforms. Clearly, such hydro-elastic phenomena couple with the "dry" aeroservo-elastic part of the machine, giving rise to a complex scenario with multiple interacting fields operating at similar bandwidths. The design of modern large and slender offshore wind turbines is based on the sophisticated knowledge of such phenomena; furthermore, control laws must be designed for the reduction of loads and vibrations on such systems, which is crucial for their safe and effective operation and for the extension of their fatigue life [5].

Yaw, torque and pitch control are the mode most often used in wind power generation [15]-[17]. Eventually, more active aerodynamic control devices or vibration control devices may also be placed on blades or tower, which will require additional design code and control system development. In order to mitigate the dynamic loads, it is generally accepted the need of allowing inelastic deformations in structures.

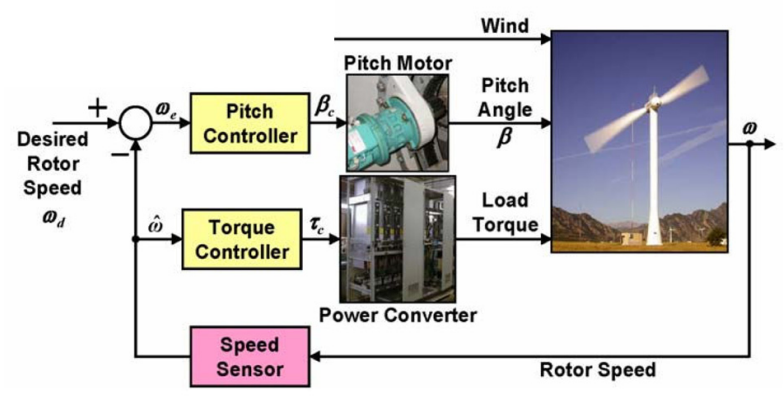

Figure 10: Wind turbine torques and pitch control

A major difficulty in the control of floating offshore wind turbine is the presence of stochastic aerodynamic load (e.g. turbulent wind) and hydrodynamic load (e.g. wave current), which requires new methodologies and tools for modeling and design of control systems and some innovative control devices for dynamic load mitigation [18]. One of the most visible and effective ways is to place a tuned liquid column damper - TLCD [19]-[20] on top of the structure.

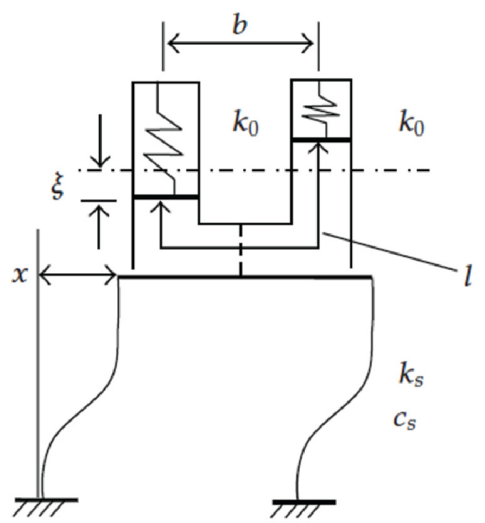

Figure 11: Tuned Liquid Column Damper (TLCD) 
TLCD in its original form is a passive damper, which is consistent over a wide range of vibration excitation levels and proves highly volumetric efficiency.

With the addition of a controllable valve to the TLCD it turns into a semiactive damper. With a suitable control law, it is possible to adapt the orifice opening according to the structure response and loading conditions.

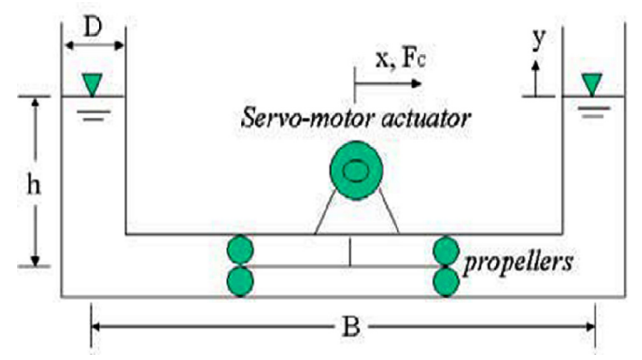

Figure 12: Semiactive TLCD

A semiactive TLCD system [21]-[28] is integrated with viscous fluid to overcome the shortcomings of the passive TLCD system and enhance its reliability and vibration reduction capability. A semiactive TLCD system is inherently reliable and can operate on very small power, e.g. a battery, without having to rely on a large external electric power. One of most promising smart liquid column damper is the MRTLCD that is a U-shape TLCD using magnetorhelogical fluid. The formation of columnar structures in an MRTLCD as result of a magnetic field will act like an instantaneously variable orifice to an extent and restrict flow in the MRTLCD, allowing the semiactive control of the structure-MRTLCD system.

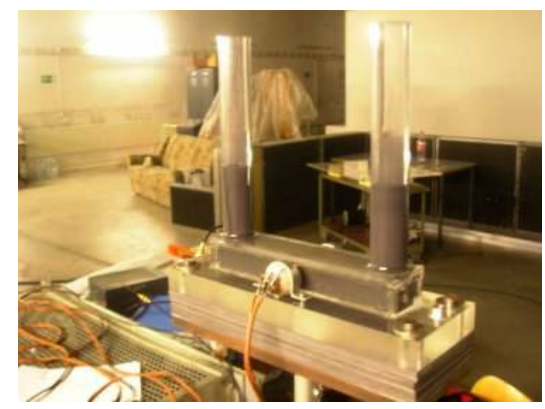

Figure 12: Magnetorheological TLCD

In this research, consider the following schematic of the combined offshore wind turbine tower and TLCD with a semiactively controllable valve.

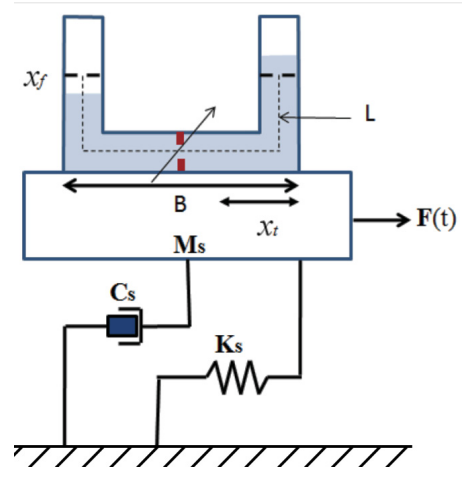

Figure 14: Semiactive TLCD for offshore wind turbine control
The dynamics of this damper can be modeled as [21]:

$$
\begin{aligned}
& \rho A L \ddot{x}_{f}(t)+\frac{1}{2} \rho A \xi(t)\left|\dot{x}_{f}(t)\right| \dot{x}_{f}(t) \\
& +2 \rho A g x_{f}(t)=-\rho A B . \ddot{x}_{t}(t)
\end{aligned}
$$

where $x_{f}(t)$ is the variation (displacement) in elevation of the liquid column, $x_{t}(t)$ is the displacement at the top of the tower, $\rho$ is the liquid density, $A$ is the cross-section area of the tube, $\mathrm{L}$ is the length of the liquid column, $\xi(t)$ is the head loss coefficient, $g$ is the gravitational acceleration and $B$ is the horizontal column length. The tower can be modeled as an $m$-degree of freedom system. The dynamics of the combined tower-TLCD system is represented by the following equation:

$$
\begin{aligned}
& {\left[\begin{array}{cc}
M_{s}+m_{f} I & \alpha m_{0} \\
\alpha m_{0}^{T} & m_{f}
\end{array}\right] \cdot\left[\begin{array}{c}
\ddot{x}_{s}(t) \\
\ddot{x}_{f}(t)
\end{array}\right]+\left[\begin{array}{cc}
C_{s} & 0 \\
0 & 0
\end{array}\right] \cdot\left[\begin{array}{l}
\dot{x}_{s}(t) \\
\dot{x}_{f}(t)
\end{array}\right]} \\
& +\left[\begin{array}{cc}
K_{s} & 0 \\
0 & 0
\end{array}\right] \cdot\left[\begin{array}{c}
x_{s}(t) \\
x_{f}(t)
\end{array}\right]=\left[\begin{array}{c}
F(t) \\
0
\end{array}\right]+\left[\begin{array}{l}
0 \\
1
\end{array}\right] \cdot u(t)
\end{aligned}
$$

where $x_{s}(t)$ is the displacement vector of the tower structure, $M_{s}$ is the mass matrix of the structure, $C_{s}$ is the damping coefficient matrix of the structure, $K_{s}$ is the stiffness matrix of the structure, $F(t)$ is the disturbance input vector. On the other hand, $m_{0}=\left[0,0, \ldots, m_{f}\right]^{\mathrm{T}}, m_{f}$ $=\rho A L$ is the mass of the column liquid, $I$ is the identity matrix, $\alpha=B / L$ is the horizontal length to column length ratio and $k_{f}=2 \rho \mathrm{Ag}$ is associated to the stiffness of the liquid column. The constraint $\left|x_{f}(t)\right| \leq(L-B) / 2$ is applied to keep the water inside the vertical sections at all times.

The control input $u(t)$ is the damping force provided by the LCD and is related to the controllable valve in the following way:

$$
u(t)=-\frac{1}{2} \rho A \xi(t)\left|\dot{x}_{f}(t)\right| \dot{x}_{f}(t)
$$

where the head loss coefficient $\xi(t)$ is dependent on the valve opening and the valve conductance. Usually, valve suppliers provide the characteristic curves. The head loss is defined as

$$
h_{f}(t)=\xi(t) x_{f}^{2}(t) /(2 g)
$$

In this way, by manipulating the ratio of the valve opening, it is possible to vary the damping force of the TLCD given by (3). Finally, the control force is regulated by varying the coefficient of head loss as an on-off control in accordance with the semiactive control strategy given as follows:

$$
\begin{array}{lll}
\xi(t)=\xi_{\max } & \text { if } & u(t) \dot{x}_{f}(t)<0 \\
\xi(t)=\xi_{\min } & \text { if } & u(t) \dot{x}_{f}(t) \geq 0
\end{array}
$$

where $\xi_{\text {min }}$ can be taken as zero because this corresponds to the fully opened valve. It can be expected that a small value of $\xi_{\max }$ will result in a lower level of response reduction.

A static $\mathrm{H}_{2} / \mathrm{H}_{\infty}$ output feedback control law has been designed in order to achieve the simplicity of controller 
implementation and provide with the prescribed performance of the semiactively controlled system:

$$
\sup _{w \in L_{2}, w \neq 0} \frac{\|z(t)\|_{2}^{2}}{\|w(t)\|_{2}^{2}} \leq \gamma^{2}
$$

in other word, the $H_{\infty}$ performance measure satisfies:

$$
J_{\infty}=\int_{0}^{\infty}\left(z^{T} z-\gamma^{2} w^{T} w\right) d t<0
$$

where $x(t)=\left[x_{s}(t), x_{f}(t), \dot{x}_{s}(t), \dot{x}_{f}(t)\right], \quad z(t)=\left[\lambda_{1} \ddot{x}_{s}(t), \lambda_{2} x_{s}(t)\right]$, $w(t)$ is the disturbance input induced by the wind and wave loads.

\section{Acknowledgment}

This work has been partially funded by the Ministry of Science and Innovation of Spain under the grant of the research project DPI2011-27567-C02-01 and by the Government of Catalonia through SGR523.

\section{References}

[1] W. Musial, S. Butterfield, Energy from offshore wind, Offshore Technology Conf., Houston, 2006.

[2] M. Kühn, Dynamics and design optimisation of offshore wind energy conversion system, PhD thesis, Delft University of Technology, 2001.

[3] K.E. Johnson, L.Y. Pao, M.J. Balas, L.J. Fingersh, Control of variable-speed wind turbines: standard and adaptive techniques for maximizing energy capture, IEEE Control Systems Magazine, 26(3), 70-81, 2006.

[4] B. Skaare, T. Hanson, F.G. Nielsen, Integrated dynamic analysis of floating offshore wind turbines, European Wind Energy Conf. \& Exhibition, Athens, Greece, 2006.

[5] B. Skaare, T. Hanson, F.G. Nielsen, Importance of control strategies on fatigue life of floating wind turbines, Int. Conf. Offshore Mechanics and Arctic Eng., 2007.

[6] M. Klose, P. Dalhoff, K. Argyriadis, Integrated load and strength analysis for offshore wind turbines with jacket structures, Int. Offshore and Polar Eng. Conf., 2007.

[7] N.J. Tarp-Johansen, Partial safety factors and characteristic values for combined extreme wind and wave load effects, J. Solar Energy Eng., 127, 242-252, 2005.

[8] J.M. Jonkman, Dynamics modeling and loads analysis of an offshore floating wind turbine, $\mathrm{PhD}$ thesis, University of Colorado, USA, 2007.

[9] A.W. Nielsen, E.A. Hansen, Time-varying wave and current-induced scour around offshore wind turbines, Int. Conf. Offshore Mechanics \& Arctic Eng., 2007.

[10] G. Bir, J. Jonkman, Aeroelastic instabilities of large offshore and onshore wind turbines, J. Physics: Conf. The Science of Making Torque from Wind, Copenhagen, Denmark, 75, 28-31, 2007.

[11] J. Van der Tempel, Design of support structures for offshore wind turbines, $\mathrm{PhD}$ thesis, Delft University of Technology, 2006.

[12] E.N. Wayman, P.D. Sclavounos, S. Butterfield, J. Jason, W. Musial, W., Coupled dynamic modelling of floating wind turbine systems, Offshore Technology Conf., 2006.

[13] H. Suzuki, A. Sato, Load on turbine blade induced by motion of floating platform and design requirement for the platform, Int. Conf. Offshore Mechanics \& Arctic Eng., 2007.
[14] S. Shim, M.H. Kim, Rotor-floater-tether coupled dynamic analysis of offshore floating wind turbines, Int. Offshore Polar Eng. Conf., Vancouver, 455-460, 2008.

[15] L. Acho, Y. Vidal, M. Zapateiro, F. Pozo, N. Luo, Chattering control design on a variable-speed horizontalaxis wind turbine, IEEE Industry Application Society Seminar on Advanced Industrial Control Applications, Barcelona, Spain, November 7, 2011

[16] C.L. Bottasso, A. Croce, B. Savini, W. Sirchi, L. Trainelli, Aero-servo-elastic modeling and control of wind turbines using finite element multibody procedures, Multibody Systems Dynamics, 16, 291-308, 2006.

[17] C.L. Bottasso, A. Croce, B. Savini, W. Sirchi, L. Trainelli, Aeroelastic analysis and control of wind turbine generators, Eolica Expo Mediterranean, Roma, Italy, 2004.

[18] N. Luo, Semiactive control strategies for vibration reduction in smart structures, Advances in Control Systems Theory and Applications, 174-190, USTC Press, Hefei, China, 2009.

[19] K. Sakai, S. Takaeda, T. Tamaki, Tuned liquid column damper - new type device for suppression of building vibrations, Int. Conf. High-rise Buildings, 1989.

[20] S.D. Xue, J.M. Ko, Y.L. Xu, Tuned liquid column damper for suppressing pitching motion of structures, Eng. Structures, 23, 1538-1551, 2000.

[21] S.K. Yalla, A. Kareem, J.C. Kantor, Semi-active tuned liquid column dampers for vibration control of structures, Eng. Structures, 23, 1469-1479, 2001.

[22] S. Colwell, B. Basu, Experimental and theoretical investigations of equivalent viscous damping of structures with TLCD for different fluids, J. Structural Eng., 134, 154-163, 2008

[23] S. Colwell, B. Basu, Tuned liquid column dampers in offshore wind turbines for structural control, Eng. Structures, 31, 358-368, 2009.

[24] S.K. Yalla, A. Kareem, Optimum absorber parameters for tuned liquid column dampers, J. Structural Eng., 126, 906915, 2000.

[25] M. Zapateiro, H.R. Karimi, N. Luo, Semiactive vibration control of offshore wind turbine towers with tuned liquid column dampers using H-infinity output feedback control, IEEE Multi-conference on Systems and Control, Yokohama, Japan, September 8-10, 2010

[26] N. Luo, Smart structural control strategies for the dynamic load mitigation in floating offshore wind turbines, International Workshop on Advanced Smart Materials and Smart Structures Technology, Dalian, China, July 25-26, 2011.

[27] N. Luo, C.L. Bottasso, H.R. Karimi, M. Zapateiro, Semiactive control for floating offshore wind turbines subject to aero-hydro dynamic loads, International Conference on Renewable Energies and Power Quality, Las Palmas de Gran Canaria, Spain, April 13-15, 2011.

[28] N. Luo, C.L. Bottasso, H.R. Karimi, M. Zapateiro, Analysis and mitigation of dynamic loads in floating offshore wind turbines, Workshop on Control, Dynamics, Monitoring and Applications, Caldes de Montbui, Spain, February 7-9, 2011. 